Латышев Василий Александрович

студент

\title{
Самарин Юрий Николаевич
}

д-р техн. наук, профессор

Высшая школа печати и медиаиндустрии

ФГБОУ ВО «Московский политехнический университет»

г. Москва

\section{АНАЛИЗ СОВРЕМЕННОЙ АВТОМАТИЗИРОВАННОЙ СИСТЕМЫ СКЛАДИРОВАНИЯ И ВНЕДРЕНИЕ ЕЕ НА МАШИНОСТРОИТЕЛЬНОЕ ПРЕДПРИЯТИЕ}

Аннотация: в работе рассматривается роль внедрения автоматизированной системы хранения инструмента. Анализируются существующче модели, типь систем, вылор лучшей из представленных.

Ключевые слова: учет инструмента, хранение инструмента, автоматизированная система, система хранения, инструментальный склад.

Современные промышленные предприятия характеризуются значительным удельным весом механического труда. На них используется множество различных видов инструмента и технологической оснастки, число наименований которых на крупных машиностроительных предприятиях доходит до нескольких десятков тысяч. Запас инструмента может составлять до 40\% от общей суммы средств оборота. Поэтому работа цехов, участков и рабочих мест зависит от своевременного обеспечения их различным инструментом. От качества применяемого инструмента зависят производительность труда, себестоимость продукции, качество продукции и другие показатели.

Основная составляющая оптимизации склада - автоматизация позволяющая эффективно управлять запасами, снижать затраты при планировании будущих закупок, оптимизировать использование складских площадей, повышать точность и оперативность учета продукции, а также производительность труда. 
Автоматизация склада предприятия включает комплекс мероприятий, таких как:

1. Оснащение склада необходимыми техническими средствами.

2. Разработка и внедрение комплексной базы данных автоматизированной системы хранения.

3. Изменение организации работы склада в соответствии с новыми требованиями.

Практически любое предприятие располагает складом, однако далеко не каждое из них планирует и может внедрять автоматизированную систему хранения.

Автоматизация производства - это применение комплекса средств, позволяющих осуществлять производственные процессы без непосредственного участия человека, но под его контролем [2].

Одно из крупнейших машиностроительных предприятий России по производству авиациионных двигателей характеризуется серийным типом производства. На предприятии для изготовления различных изделий используется как специализированное, так и универсальное оборудование. Одни операции выполняются с большей степенью ручных работ (например, наиболее трудоемкими здесь являются сборочные операции), другие - более механизированы.

Общее количество работников на предприятии составляет более 8000 человек. Среди разных вспомогательных производств на предприятии существует собственное инструментальное производство. Значительная номенклатура технологической оснастки предопределяет сложность организации работ по стадиям ее жизненного цикла и функциям управления.

Состав инструментального склада зависит от конструкторских и технологических особенностей продукции, размера предприятия и типа производства. В состав системы по хранению и распределению инструмента входят:

1) инструментальный отдел;

2) инструментальный цех;

3) центральный инструментальный склад (ЦИС);

4) цеховые инструментально-раздаточные кладовые (ИРК); 
5) участок изготовления приспособлений;

6) заточной цех;

7) ремонтная служба.

Инструментальный цех обеспечивает и определяет потребность предприятия в инструменте и оснастки, составляет планы по его изготовлению, осуществляет контроль, за хранением и использованием инструмента и оснастки, проводит его классификацию и индексацию, осуществляет проектирование и разрабатывает технологию изготовления технологического инструмента и оснастки.

Основными задачами инструментальной кладовой являются:

- своевременное и бесперебойное обеспечение инструментом всех цехов и рабочих мест;

- организация рациональной эксплуатации инструмента и сокращение его расходов;

- сокращение затрат на изготовление, приобретение, хранение и ремонт инструмента;

- -поддержание оптимальных запасов инструмента [2].

От правильной организации инструментального склада зависит эффективность работы предприятия, т.е. качество продукции, интенсивность производства, прибыль и рентабельность.

Общая потребность в инструменте на плановый период складывается из расходного и оборотного фондов, т.е.

$$
I_{\text {обш. }}=I_{p}+\left(I_{\text {об. н. }}-I_{\text {об. ф. })}\right.
$$

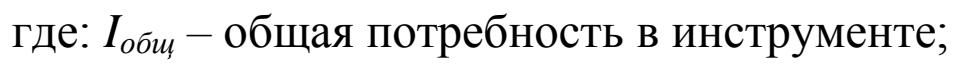

$I_{p}$ - расходный фонд инструмента;

$I_{\text {об.н }}$ - норматив оборотного фонда инструмента на начало планового периода;

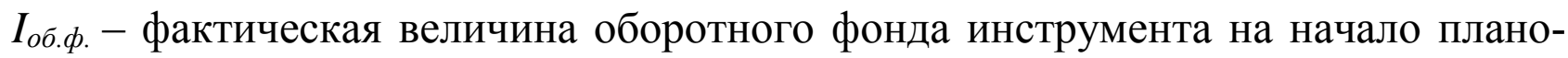
вого периода.

Оборотный фонд - это та часть инструмента, которая необходима предприятию для бесперебойной его работы [1]. 
Затем определяют потребность в каждом типоразмере инструмента данной типовой группы по формуле:

$$
I_{\mathrm{p}}=\frac{F_{\mathrm{M}} \cdot k_{n} \cdot i}{t_{\text {изн }} \cdot\left(1-k_{\text {уб}}\right)}
$$

где: $I_{\mathrm{p}}$ - расходный фонд инструмента данного типоразмера, шт.;

$F_{\text {м }}$ - годовой фонд машинного времени данной группы однородных станков, час.; $k_{n}$ - коэффициент применяемости данного типоразмера инструмента в фонде машинного времени;

$i$ - число инструментов данного типа одновременно работающих на станке, шт.; $t_{\text {изн }}$ - время работы инструмента до полного износа, час.;

$k_{\text {уб }}-$ коэффициент случайной убыли инструмента.

Для обеспечения безостановочной работы цехов необходимо иметь и постоянно оборачиваемый фонд инструмента. Общезаводской оборачиваемый фонд инструмента по каждому виду и типоразмеру определяется по формуле:

$$
Q_{\text {общ.зав. }}=\sum_{i=1}^{m} Q_{\text {цех } 1}+Q_{\text {цис }}
$$

где: $Q_{\text {общ.зав. }}$ общезаводской оборотный фонд инструмента;

$Q_{ц е х 1}-$ оборотный фонд инструмента $i$-го цеха;

$m$ - количество цехов на предприятии;

$Q_{\text {цис }}$ - оборотный фонд инструмента центрального инструмента склада (ЦИС).

Постоянно необходимый инструмент цеха определяется так:

$$
Q_{\text {цех }}=Q_{\text {р.м. }}+Q_{\text {з.р. }}+Q_{\text {иРК }}
$$

где: $Q_{\text {р.м. }}-$ инструмент, находящийся на рабочих местах;

$Q_{\text {з.р. }}$ - инструмент, находящийся в заточке и ремонте;

$Q_{\text {ирк }}-$ инструмент, находящийся в инструментально-раздаточной кладовой (ИРК).

Страховой запас создается с целью обеспечения рабочих мест инструментом на случай запаздывания очередной партии поставки инструмента. Обычно 
страховой запас берется в размере 5 - $10 \%$ от максимального переходящего запаса [2].

Планирование запаса инструмента по системе максимум - минимум может быть организованно для инструмента, расходуемого в больших количествах [2].

При всем многообразии используемого инструмента на производстве необходимо использовать автоматизированные склады.

Уровень современного оборудования и инженерной мысли позволяет это сделать. Автоматизированные склады могут разместить максимальное количество инструмента на минимальной площади и обладают следующими преимуществами:

1. Экономия места и производительность. Система обеспечивает максимально эффективное хранение и высокую производительность. Автоматизированный склад повышает производительность более чем на $100 \%$ в сравнении с ручными системами обработки (стеллажи, поперечные шкафы, выдвижные ящики).

2. Защита и контроль. Система надёжно убережёт дорогостоящий инструмент и располагает целым набором внутренних средств защиты.

3. Доступность и эргономика. Автоматизированный склад удобен и прост в использовании и доступен для любого персонала. Система исключает возможность получения травмы, поскольку не требует выполнения ручных работ (например, перестановки и открытия грузов).

4. Максимальная грузоподъёмность на минимальной площади.

5. Большой объём при малом занимаемом пространстве [3.]

Выбор складской системы (автоматизированного склада) проходил по заданию.

По оборудованию были следующие требования:

- высота устанавливаемого оборудования должна быть 4500-4600 мм;

- ширина не должна превышать 2500 мм;

- глубина не должна превышать 3000 мм;

- возможность подключения считывателя маркировок; 
- возможность использования своих контейнеров для хранения;

- максимально допустимая высота хранимого инструмента 700 мм;

- русскоязычный интерфейс;

- свой уровень доступа для конкретного сотрудника;

- возможность ведение фото- и видеосъемки извлекаемого инструмента.

Между карусельной системой и лифтовой системой склада была выбрана лифтовая система.

Лифтовая система подошла лучше, так как специальные считыватели позволяют определить высоту хранимого инструмента, и поместить стеллаж с инструментом в подходящее место, что позволяет более эффективно использовать место для хранения. Лифтовая система быстрее подводит стеллаж к оператору и не требуется прокрутки всех стеллажей как в карусельном типе системы. Программное обеспечение позволяет записывать специальные ключи с различными уровнями доступа (определяемый администратором), и по конкретному ключу доступен определенный стеллаж. При дополнительном оснащении возможно ограничение доступа по ячейкам [3].

В результате просчетов количества возможно хранимого инструмента было заказано и установлено две автоматизированных системы хранения.

Система автоматизированного склада имеет высокую стоимость, но нужно учесть, что она занимает в 4 раза меньше места чем занимал до этого обычный склад. Освободилось место для установки нового оборудования с ЧПУ. В его обслуживании занят один человек (оператор) и администратор. До этого на складе работало 4 человека: инженер по инструменту (в данный момент администратор) и три кладовых работника (сейчас они переведены на другие должности). По расчетам данное оборудование окупит себя через 5 лет. Сейчас поиск инструмента в среднем занимает 2 мин вместо обычных 10-15 мин. За счет автоматического учета мы отказались от использования карточек учета инструмента. Ведется точный учет оставшегося инструмента и количество не востребованного. При переходе на автоматизированное хранение были выявлены все недостачи и переизбытки инструмента. И при смене оператора новый оператор будет в курсе всего 
количества хранимого инструмента, на данный момент это более 10000 наименований.

В дальнейшем планируется запуск автоматизированного внесения инструмента не со стойки автоматизированной системы склада, а с рабочего места. С помощью стационарного компьютера или с помощью считывателя штрих-кодов расположенного на пульте управления и подключенного к компьютеру (с использованием стандартных штрих-кодов, присвоенные производителем и собственных сделанные самими с помощью специального оборудования).

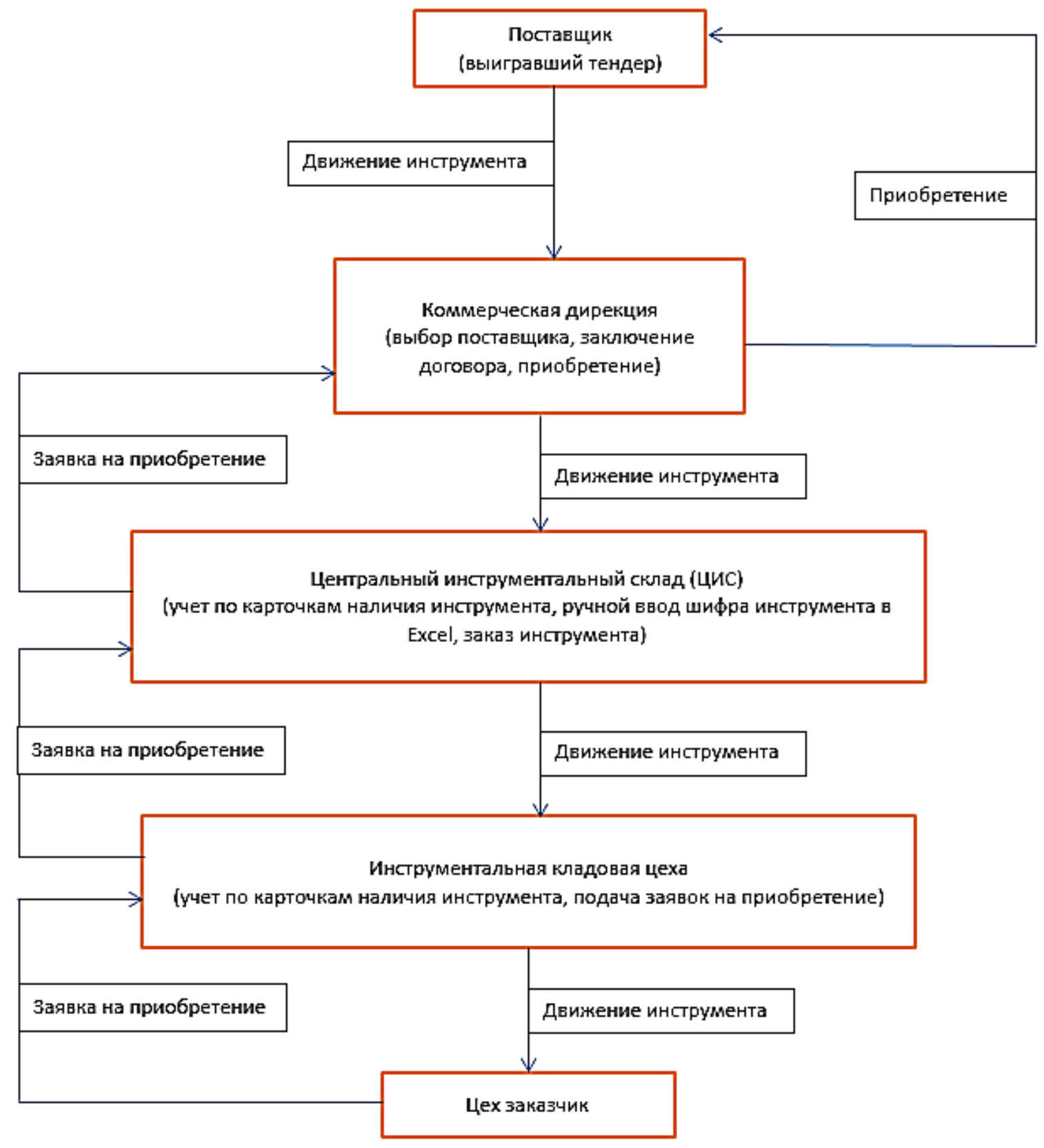

Рис. 1. Система движения инструмента «как было» 


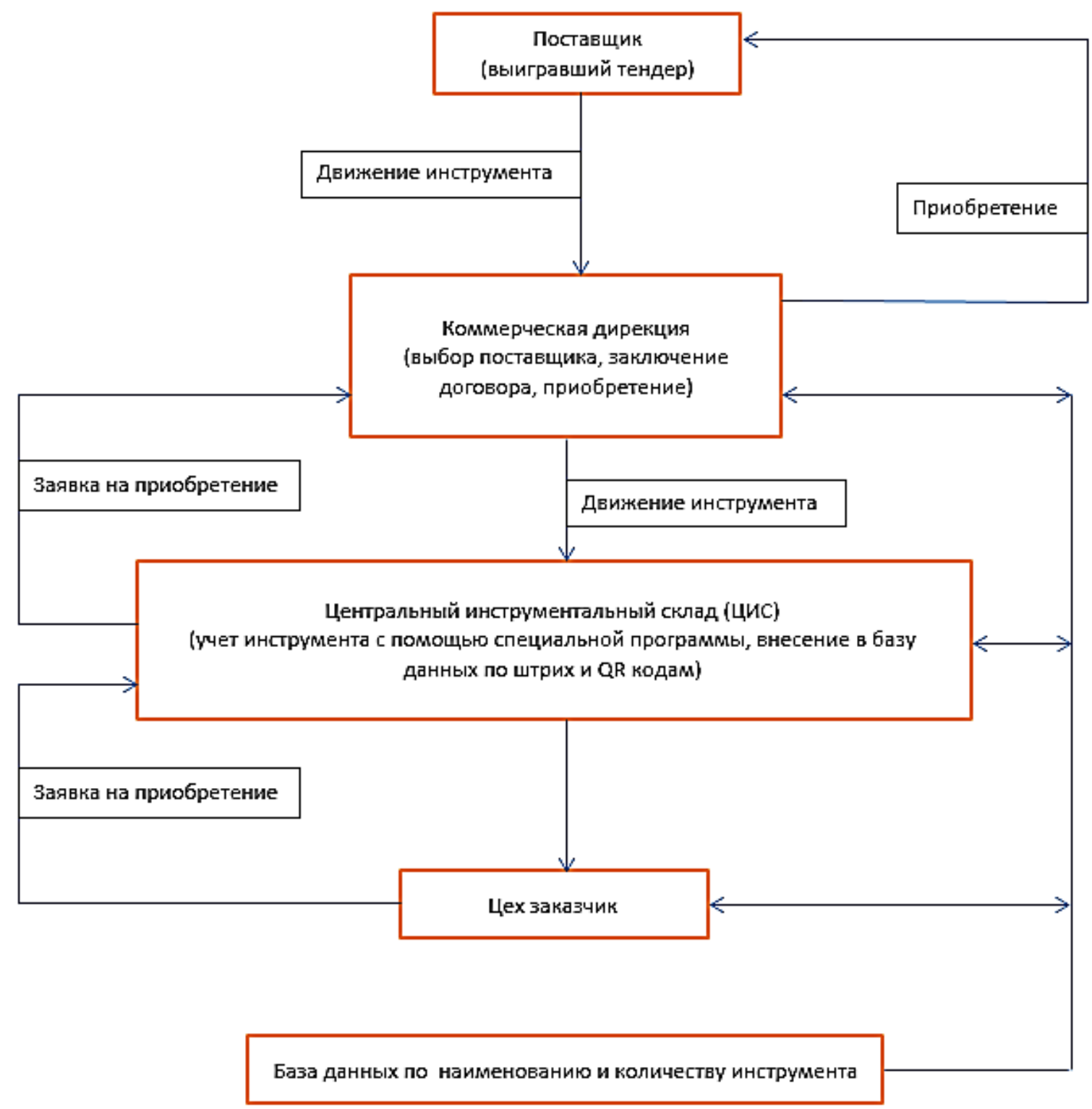

Рис. 2 Система движения инструмента «как стало»

Таким образом по данным схемам видно, что при внедрении автоматизированной системы хранения инструмента исключается в цепочке звено (инструментальная кладовая цеха). Имеется общая база данных со всем хранимым инструментом, к которому есть допуск у всех связанных структур. Тем самым уменьшается время поиска инструмента, отсутствие письменных заявок на приобретение (все проходит в электронном виде), что сокращает время получения необходимого инструмента в 2-4 раза. 


\section{Список литературы}

1. Епифанцев Ю.А. Организация технического обслуживания и ремонтов механического оборудования металлургических предприятий: Учебное пособие. - Новокузнецк: СибГИУ, 2008.

2. Организация производства и управление предприятием: Учебник / О.Г. Туровец, М.Н. Бухалков, В.Б. Родионов [и др.]; под ред. О.Г. Турова. - М.: Инфар-М, 2003.

3. [Электронный ресурс]. - Режим доступа: http://www.hanelworldwide.com/ de/en/Products/Lean-Lift\%C2\%AE.html 